\title{
The Anthropocene and Its Relationship to Planetary Health
}

\author{
Gomes da Silva MA* \\ Department of Chemistry, Federal University of Juiz de Fora, Brazil \\ *Corresponding author: Gomes da Silva MA, Department of Chemistry, Federal University of Juiz de Fora, Brazil; Email: marcosaureliojf@hotmail.com
}

Received: December 07, 2021; Accepted: December 10, 2021; Published: December 20, 2021

In recent decades, man has become a geological force, competing with natural forces in the impact and modification of the Earth system. The term Anthropocene was proposed by scientists Paul Crutzen and Eugene F. Stoemer, in 2000, to describe this new time and emphasize the preponderant role of man in geology and ecology. There is no doubt that man has unequivocally and in some cases irreversibly changed the Planet, and that Holocene concepts can no longer be used to describe trends in chemical and biological variables and the future of the Earth system as a whole. Tomorrow depends, to a great extent, on actions to optimize the relationship between man and the environment. This, then, is the moment we find ourselves in today: the Epoch of Humans. The one in which Homo sapiens finds that civilization has become a force of planetary reach and of geological duration and scope. We are billions of people in the world and we continue to multiply.

From a biological point of view, it is a growth equivalent to that of a colony of bacteria: na extremely explosive pace, in a very short period of time. We have become planetary: today there is not a single region that is not directly or indirectly affected by the whole of human activity. By releasing smoke from automobiles, chimneys and fires, humanity changed the composition of carbon in the atmosphere, causing a temperature increase of $1^{\circ} \mathrm{C}$, glaciers melting and sea level rise by, so far, 20 centimeters. Not to mention how humanity physically altered the planet, with concrete and steel. A clear example is the rivers: in the last decades, we have transformed the river courses of all the hydrographic basins of the world by building 40 thousand dams. If the reservoirs of all these dams were placed side by side, we would have a flooded area equivalent to the State of Bahia.

In na article published in the bulletin of the International Geosphere-Biosphere Program, Crutzen defended his thesis by saying that the rate of urbanization has increased tenfold in the last century and that, in a few generations, humanity will extinguish the fossil fuels generated over the last hundreds of millions of years. The text had na almost immediate repercussion among geologists. Scientist Andrew Gale of the University of Portsmouth, a member of the Geological Society of London, told The Times newspaper that he agrees with the argument of the chemist and his fellow geologists. According to him, human activities have become the main force behind the great changes in topography and climate. According to him, you cannot have 6.5 billion people living on a planet the size of ours and exploit every possible resource without causing gigantic changes in the physical, chemical and biological environments, which will be dramatically reflected in our geological record.
Citation:

Gomes da Silva MA (2021) The Anthropocene and Its Relationship to Planetary Health. J Pharmacol Pharm Res Volume 5(1): 1-1. 